\title{
Magnetic Field Distribution in a WPT System for Electric Vehicle Charging
}

Rui Feng ${ }^{1}$, Nina Roscoe ${ }^{2}$, Layth Qaseer ${ }^{1}$, Mariusz Bojarski ${ }^{1}$, Jaegue Shin ${ }^{1}$, Dariusz Czarkowski $^{1}$, Francisco De Leon ${ }^{1}$, Stephen Finney ${ }^{2}$, and Qijun Deng ${ }^{3}$

${ }^{1}$ New York University

${ }^{2}$ University of Strathclyde

${ }^{3}$ Wuhan University

Progress In Electromagnetics Research Symposium

Shanghai, 2016 


\section{Introduction}

$>$ Wireless power transfer technology has various applications.

\section{Smart phones \& Tablets}

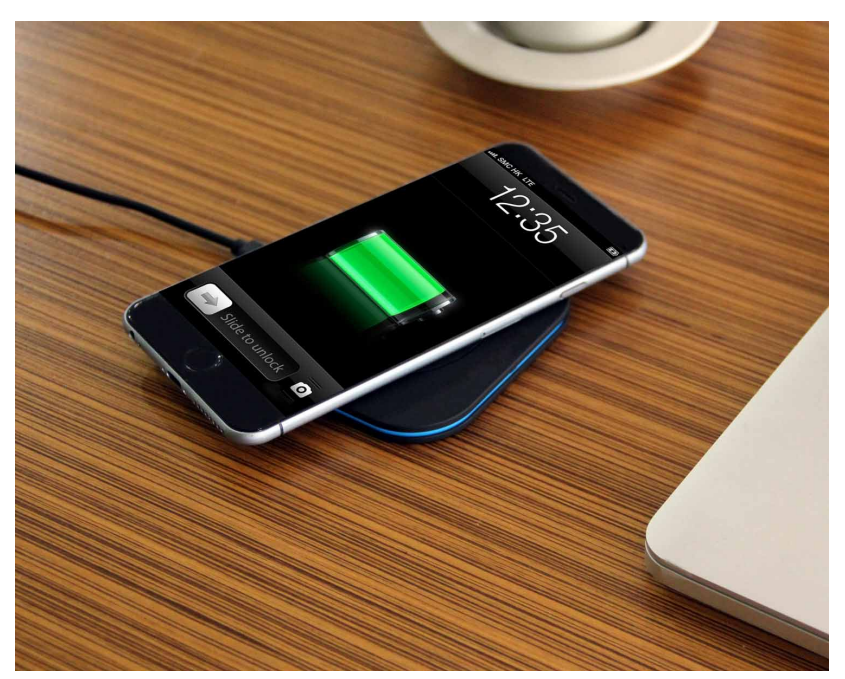

Source: www.iectechnology.com

\section{AA Battery Powered Devices}

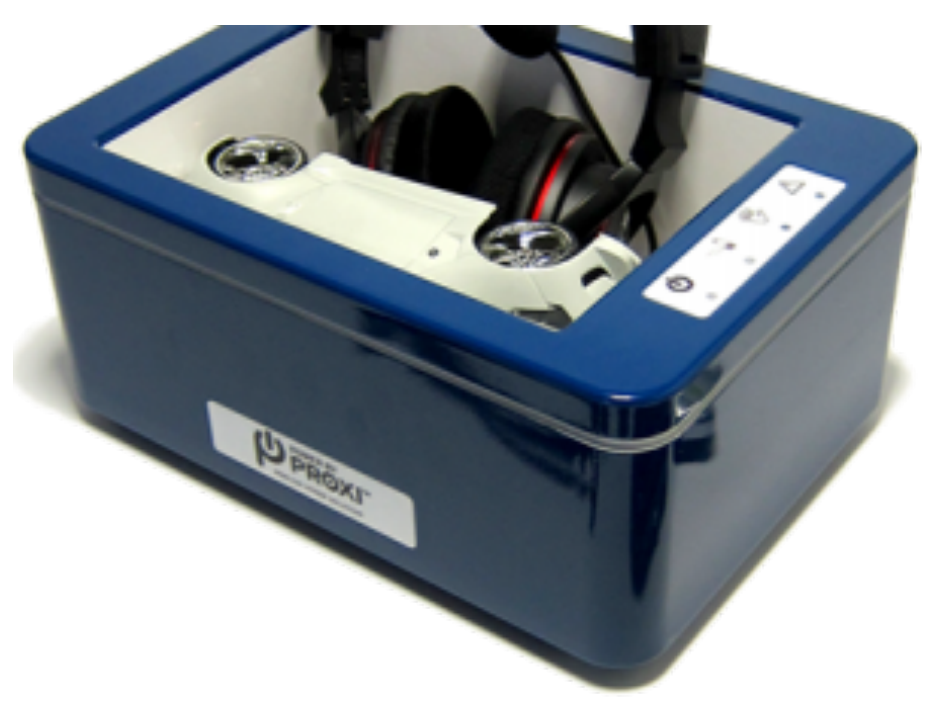

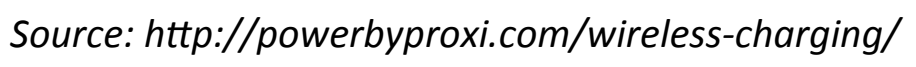




\section{Medical Devices \& Equipment}

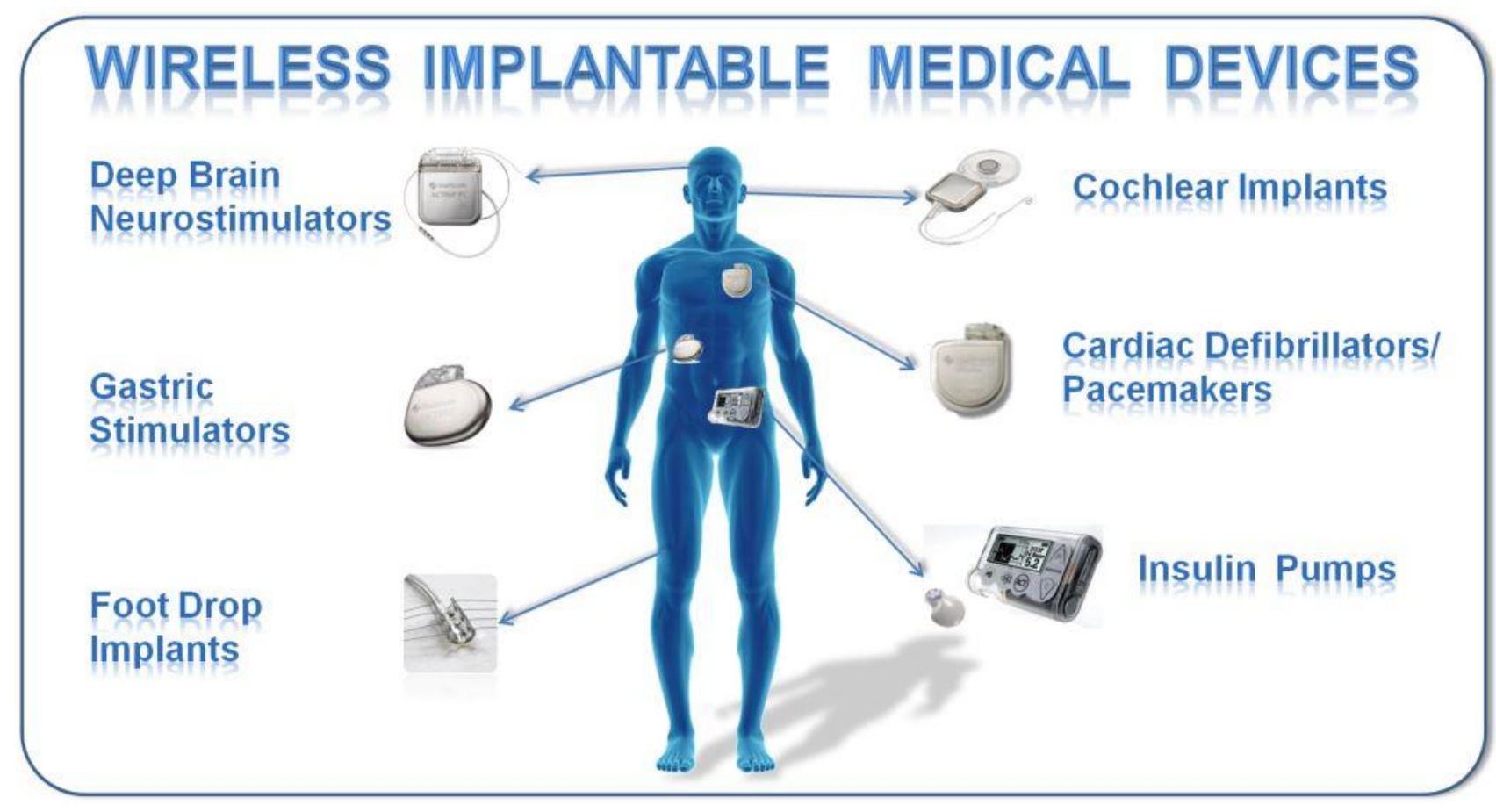

Source: rahulmittal.wordpress.com/2014/03/31/wirelesscharging-do-we-need-this-technology-in-its-current-form/ 


\section{Vehicles \& Transport}

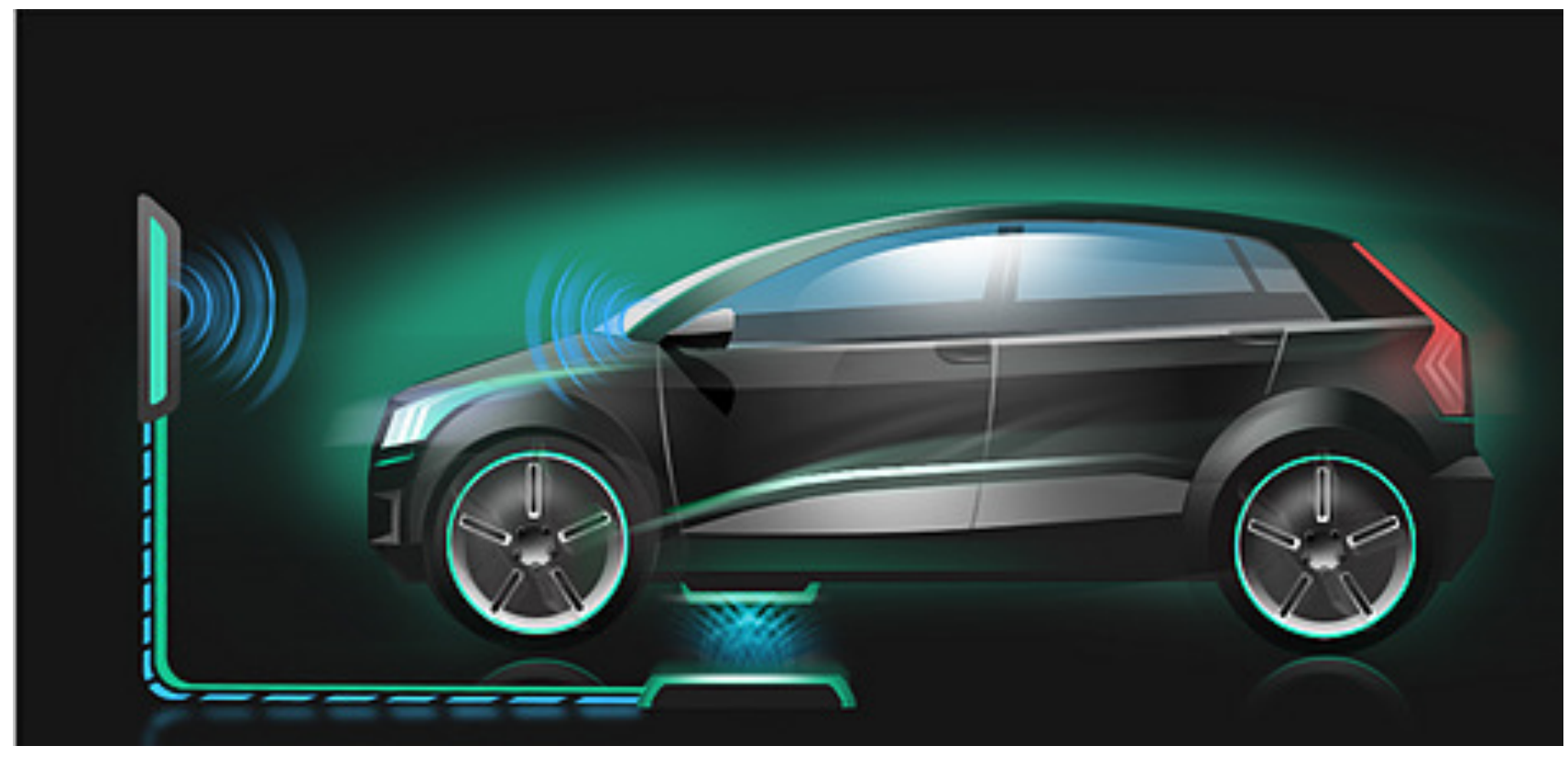

Source: $h t t p: / / a r t i c l e s . s a e . o r g / 12647 /$ 


\section{Introduction}

$>$ Wireless power transfer technology has various applications. $>$ Wireless power transfer technology has many benefits.

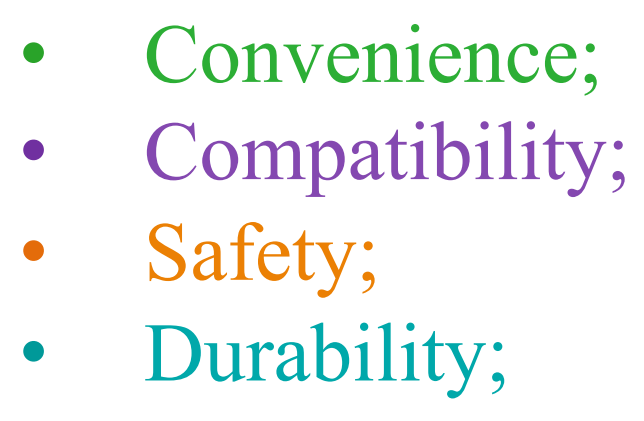




\section{Motivations}

- Efficient design of WPT for electric vehicles;

- Safety consideration of WPT system. 


\section{System Overview}

$>$ Wireless charging electric vehicle;

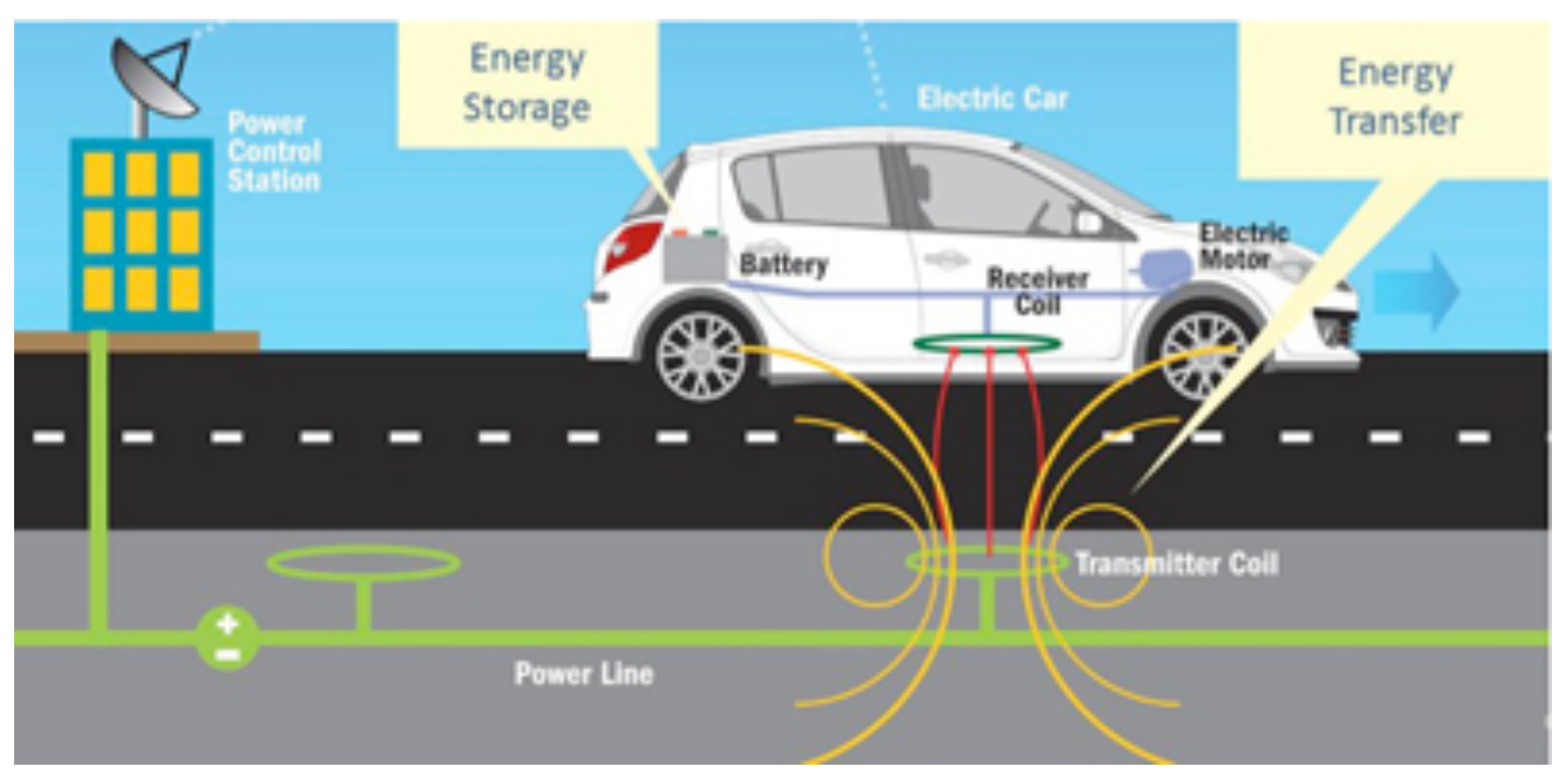




\section{System Overview}

$>$ Wireless charging electric vehicles;

$>$ Inductive coupled power transfer (ICPT) system;

- Near range

- High power efficiency

- Low frequency

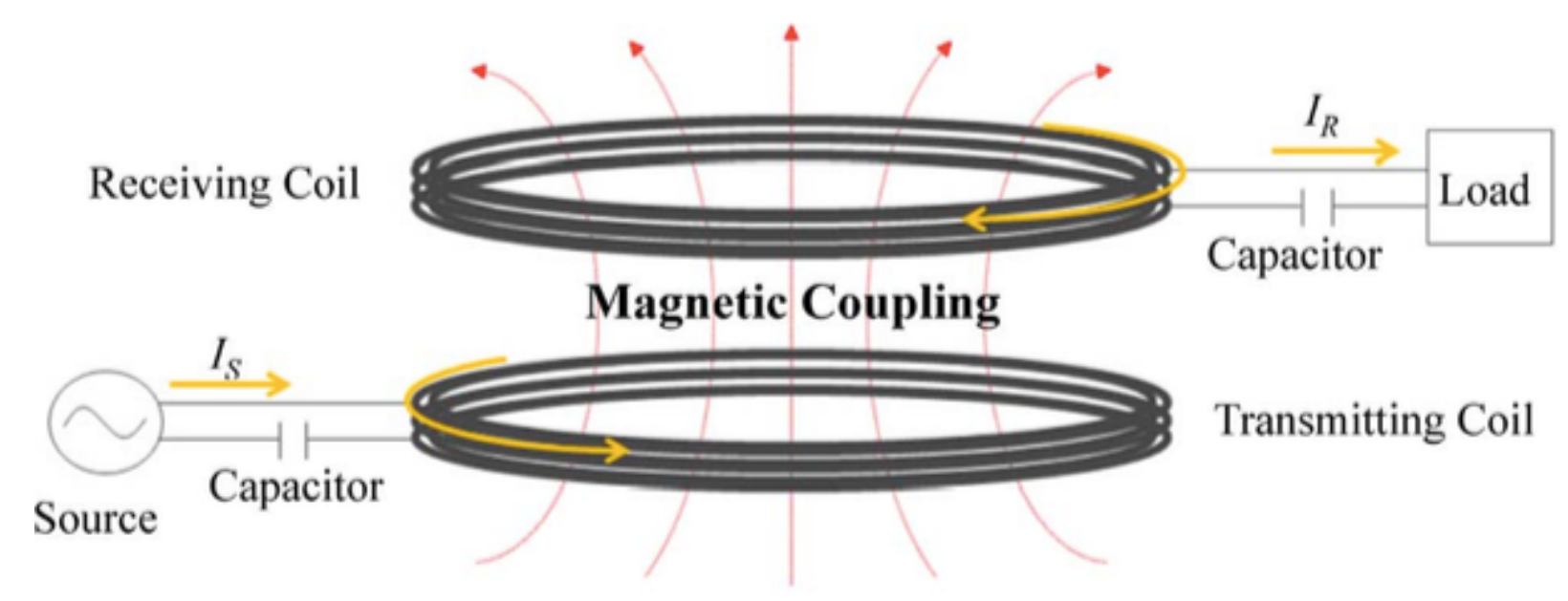


System Overview

$>$ Wireless charging electric vehicles;

$>$ Inductive coupled power transfer system;

$>3$-D finite-element analysis in system design;

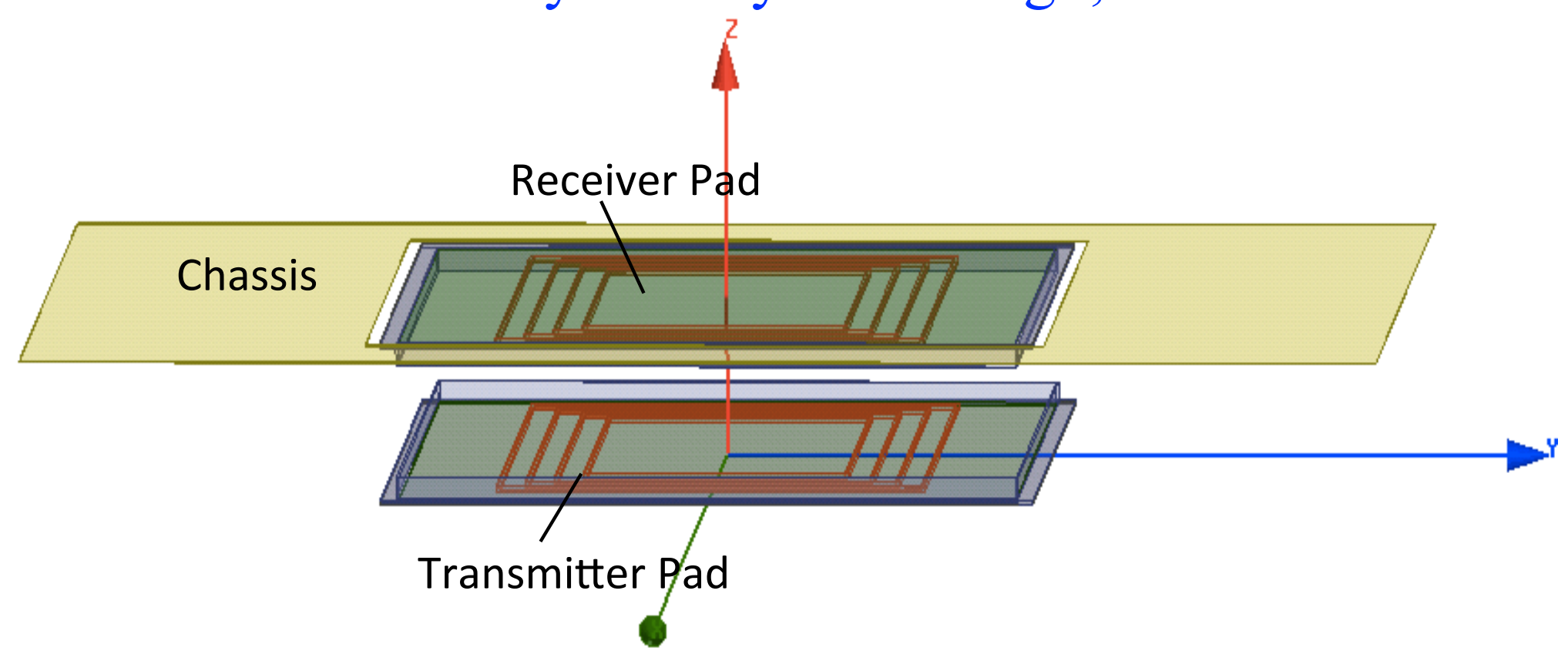

Chassis: steel sheet $(1250 \mathrm{~mm} \times 1900 \mathrm{~mm})$.

Transmitter/Receiver Pad $\left\{\begin{array}{l}\text { Copper coils (4 turns); } \\ \text { Ferrite Core (840mm x 680mm); } \\ \text { Aluminum shield }(914 \mathrm{~mm} \times 914 \mathrm{~mm}) .\end{array}\right.$ 


\section{System Overview}

$>$ Wireless charging electric vehicles;

$>$ Inductive coupled power transfer system;

$>3$-D finite-element analysis in system design;
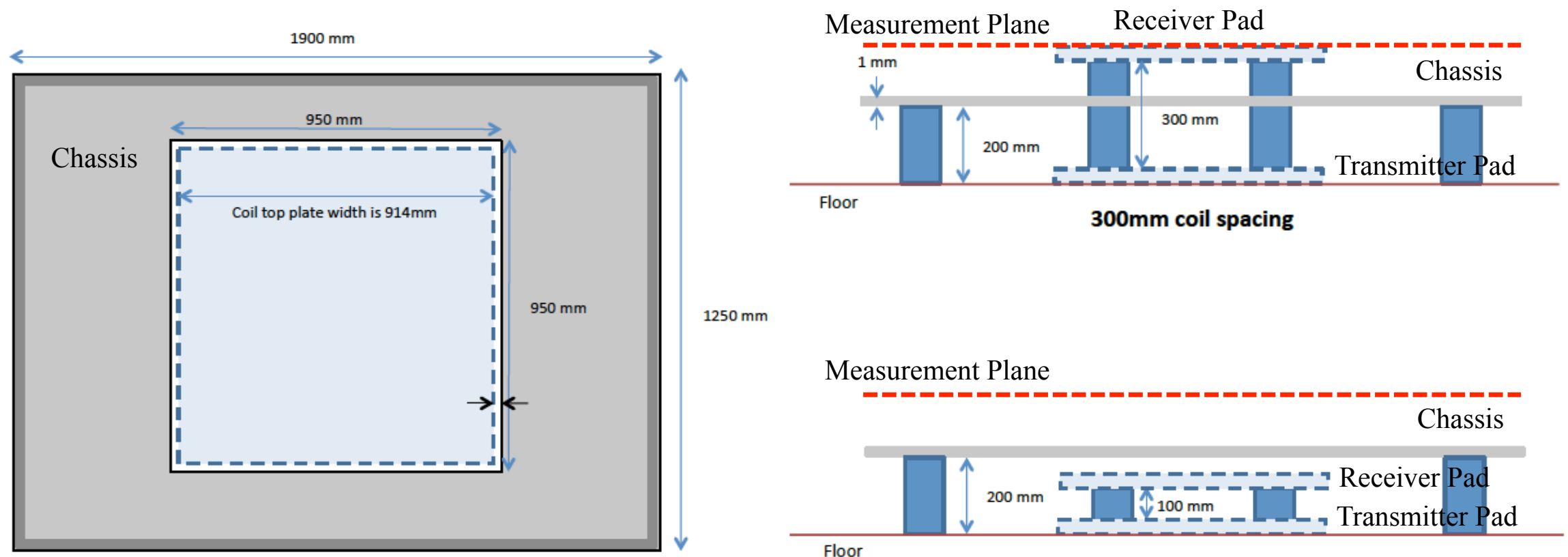

$1250 \mathrm{~mm}$

Measurement Plane

Chassis

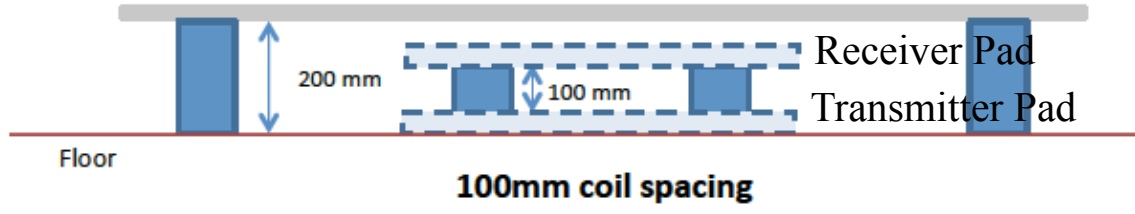


System Overview

$>$ Wireless charging electric vehicles;

$>$ Inductive coupled power transfer system;

$>3$-D finite-element analysis in system design;

$>$ Experimental system.

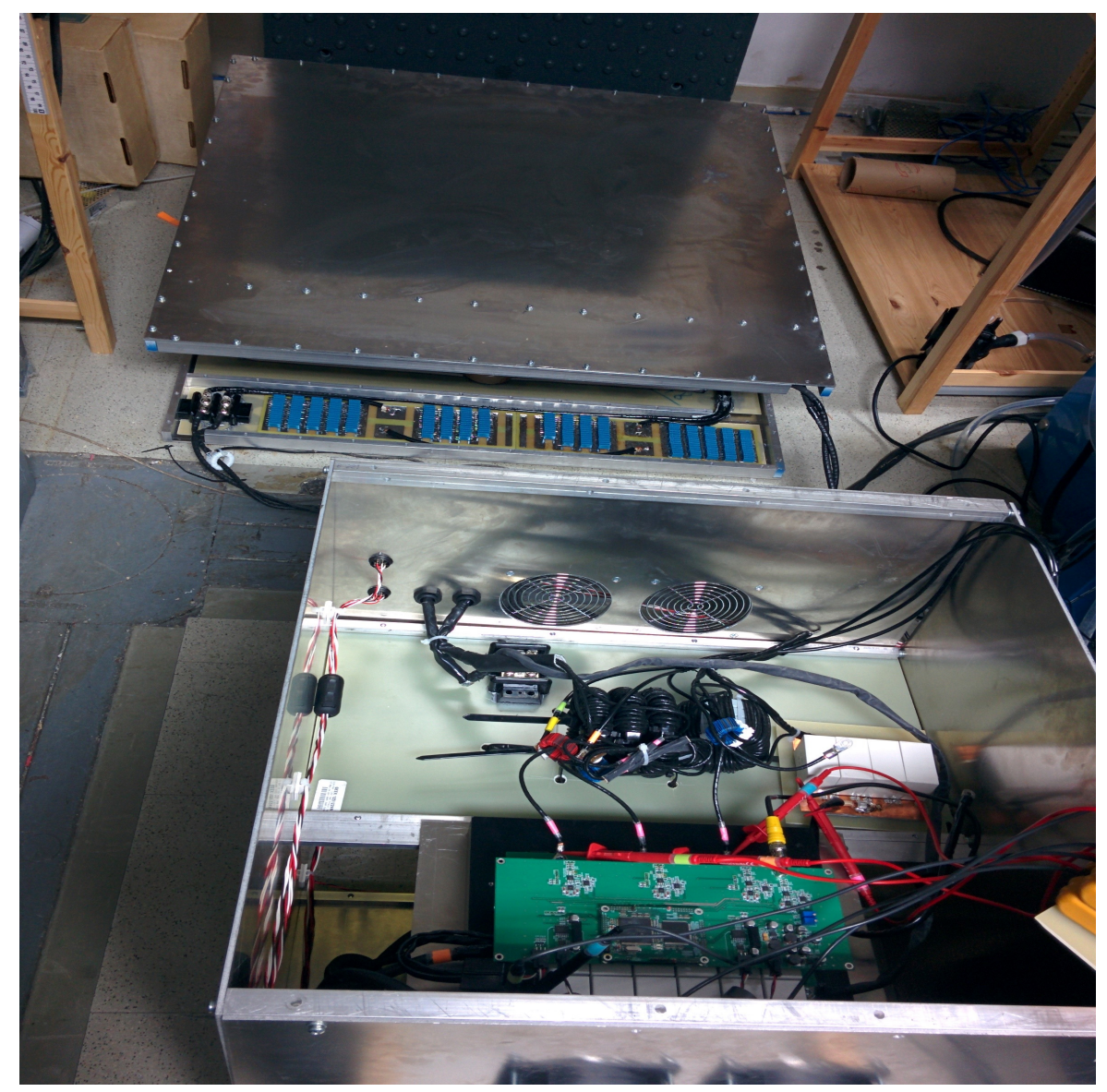




\section{Results Outline}

1) Effect of output power on magnetic field distribution (MFD)

2) Effect of coil spacing on MFD

3) Effect of chassis on MFD

4) Effect of misalignment on MFD 


\section{Effect of Output Power}

$>$ The transmitter pad and the receiver pad are perfectly aligned.

$>$ Coil spacing is $200 \mathrm{~mm}$.

$>$ Chassis is in position.

$>$ Load resistance is $5.54 \Omega$.

$>$ MFD is measured $300 \mathrm{~mm}$ above ground.

How is the magnetic field distribution for--

$5 \mathrm{~kW}, 15 \mathrm{~kW}$ and $20 \mathrm{~kW}$ output power? 


\section{Effect of Output Power}

\section{Experimental Results}
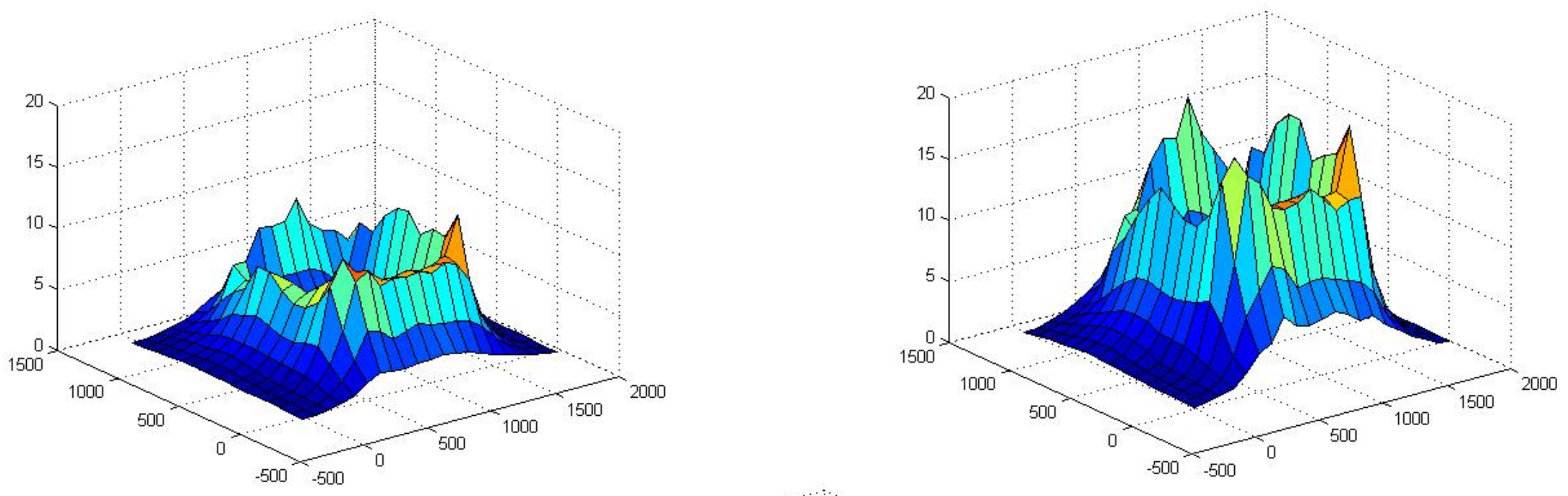

$5 \mathrm{~kW}$

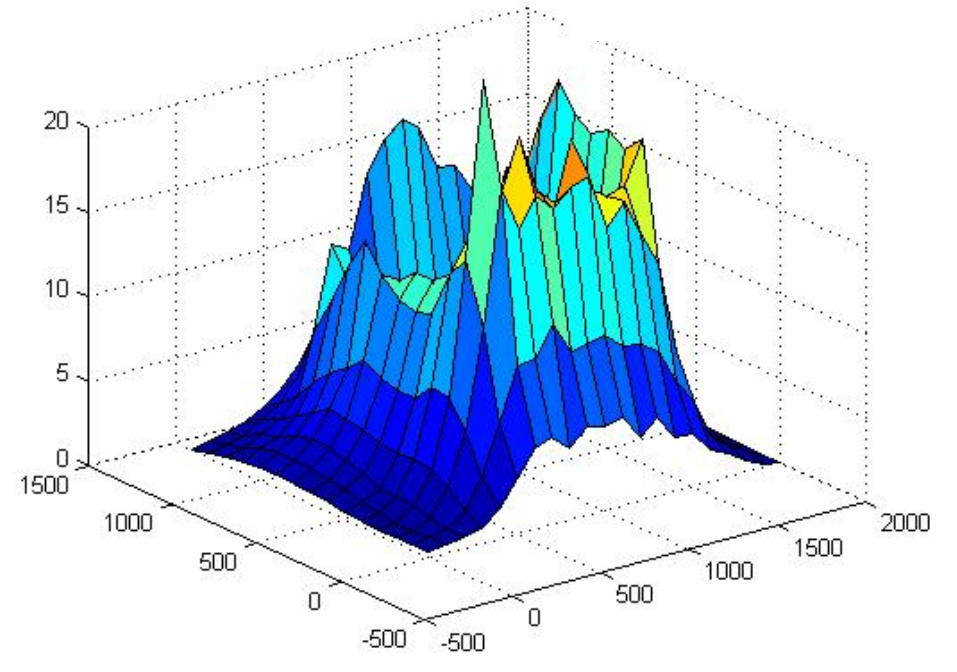

$15 \mathrm{~kW}$

$20 \mathrm{~kW}$ 


\section{Effect of Output Power}

\section{Experimental Results (Scaled to 20kW)}
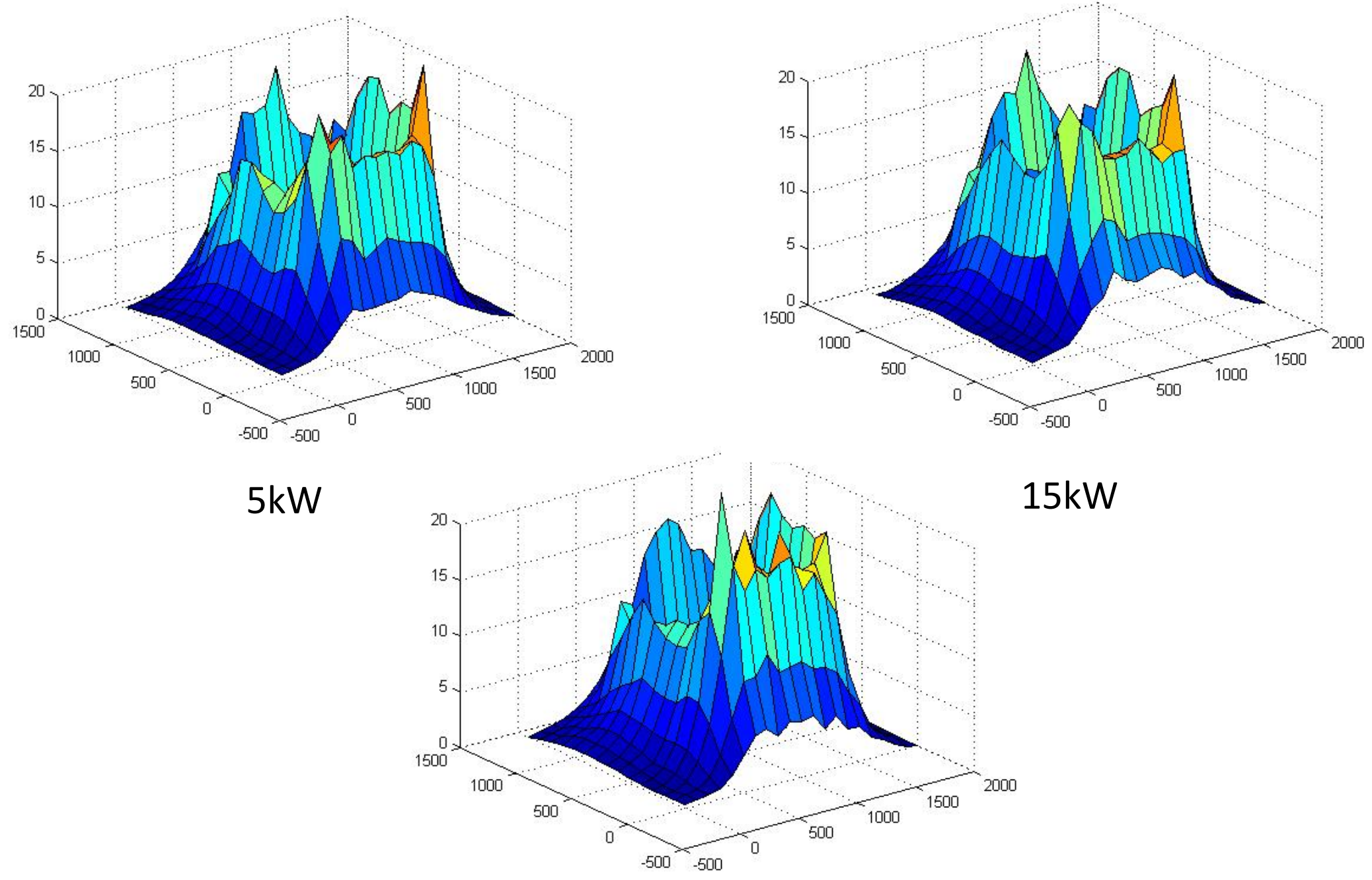

$15 \mathrm{~kW}$ 


\section{Effect of Coil Spacing}

$>$ The transmitter pad and the receiver pad are perfectly aligned.

$>$ Chassis is in position.

$>$ MFD is measured $300 \mathrm{~mm}$ above ground.

How is the magnetic field distribution for--

$100 \mathrm{~mm}, 150 \mathrm{~mm}, 200 \mathrm{~mm}$ and $250 \mathrm{~mm}$ coil spacing? 


\section{Effect of Coil Spacing}

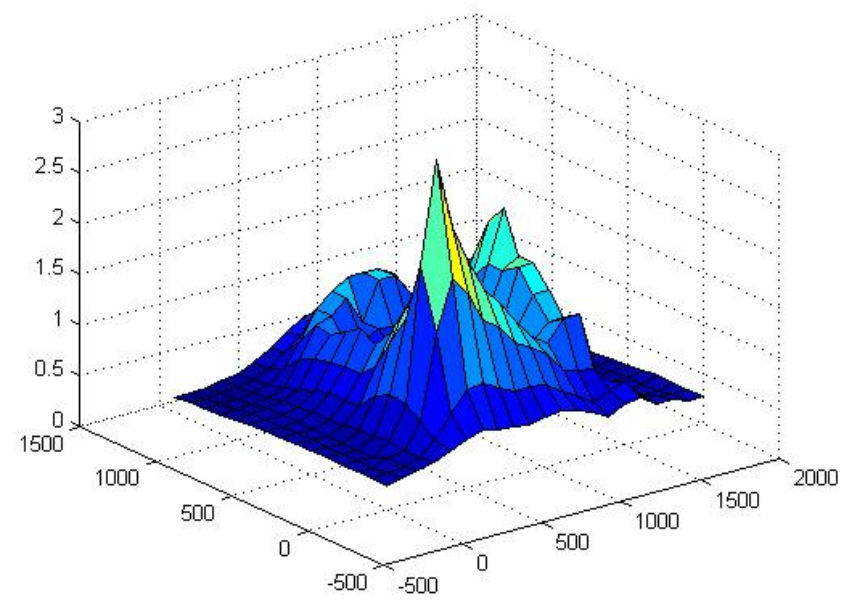

$100 \mathrm{~mm}$

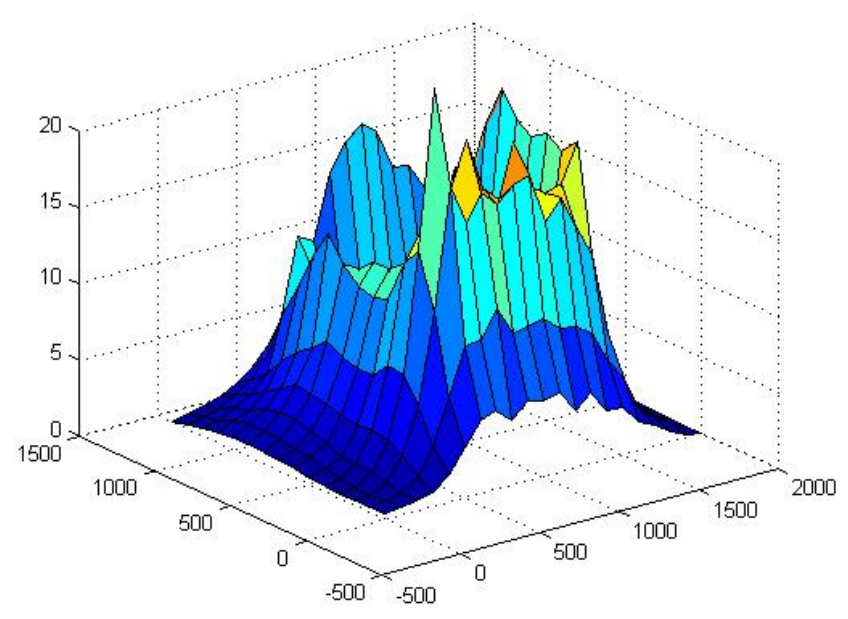

$200 \mathrm{~mm}$

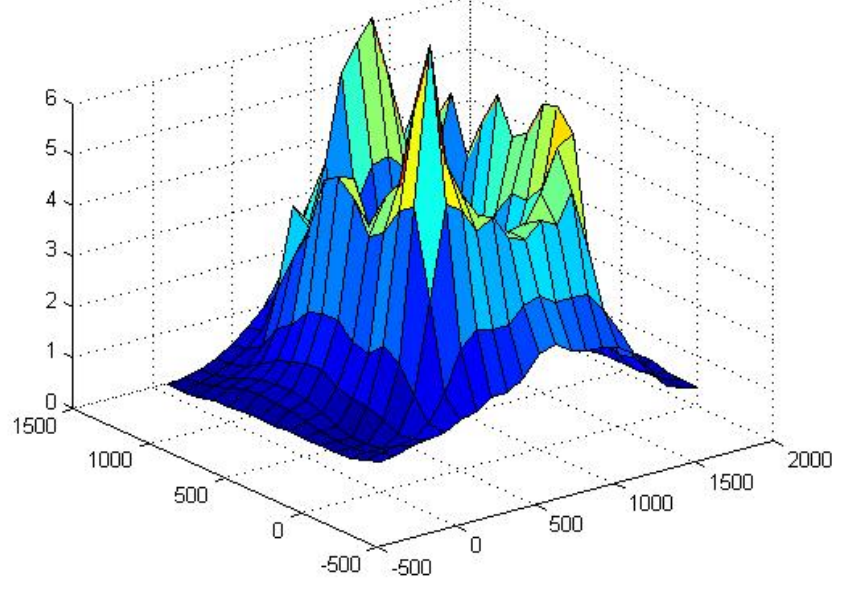

$150 \mathrm{~mm}$

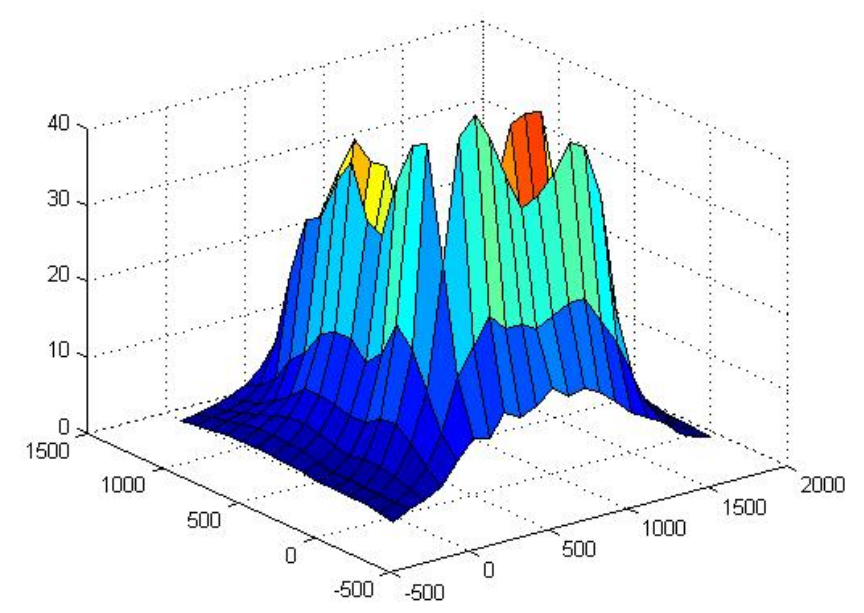

$250 \mathrm{~mm}$ 


\section{Effect of Coil Spacing}

Put all results in the same-size window. All results are scaled to $20 \mathrm{~kW}$.

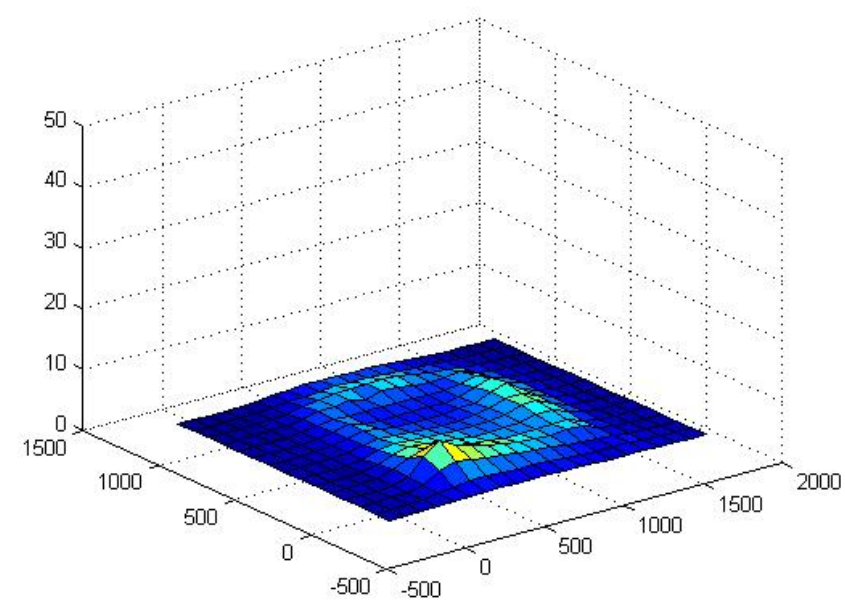

$100 \mathrm{~mm}$

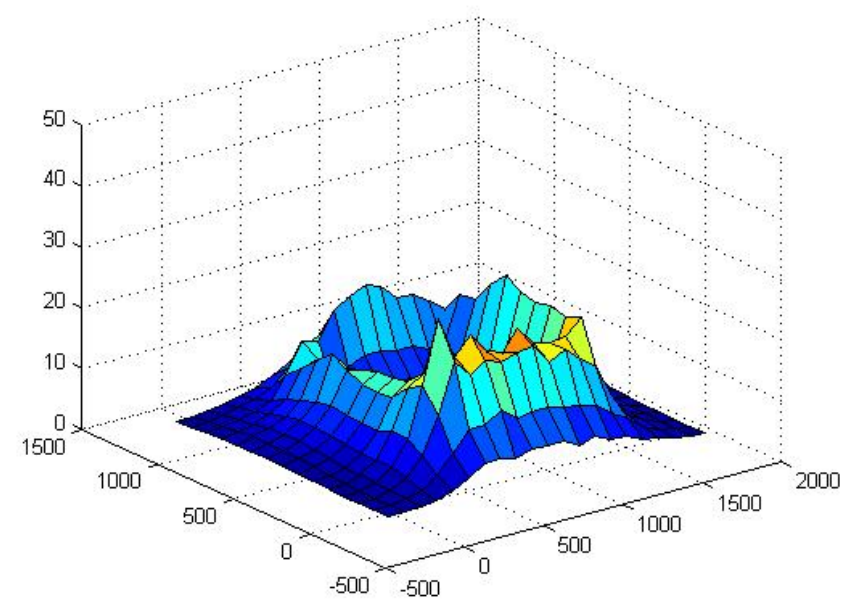

$200 \mathrm{~mm}$

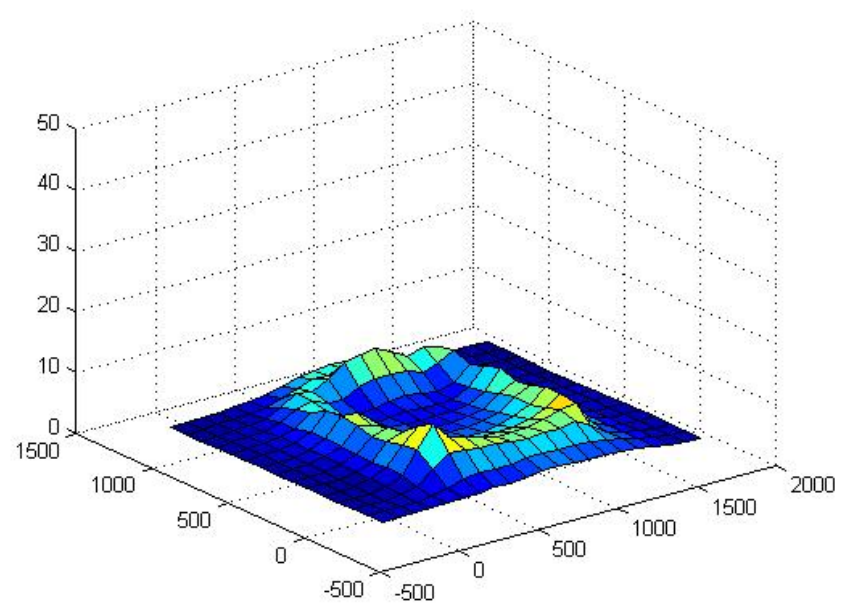

$150 \mathrm{~mm}$

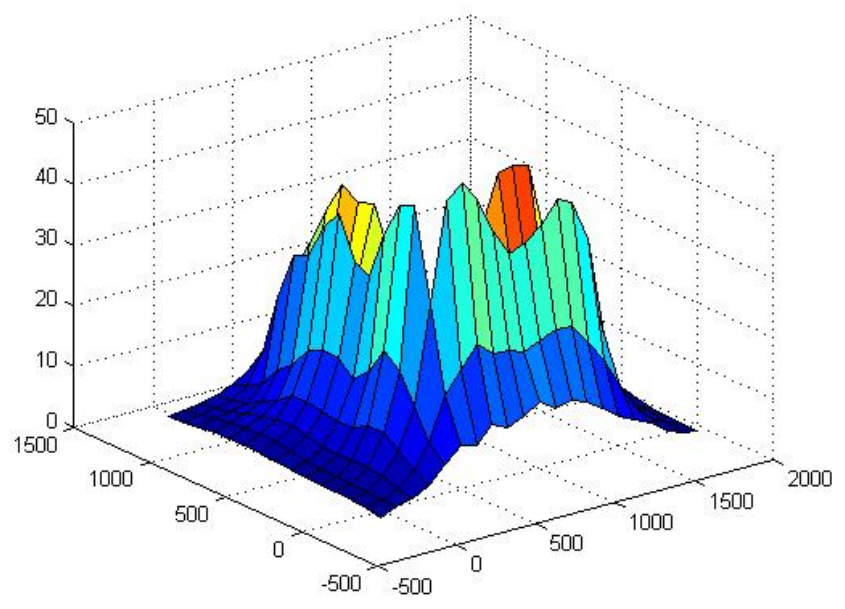

$250 \mathrm{~mm}$ 


\section{Effect of Chassis}

$>$ The transmitter pad and the receiver pad are perfectly aligned.

$>$ Coil spacing is $200 \mathrm{~mm}$.

$>$ Output power is $15 \mathrm{~kW}$.

$>$ MFD is measured $300 \mathrm{~mm}$ above ground.

How is the magnetic field distribution for--

with chassis and without chassis case? 


\section{Effect of Chassis}

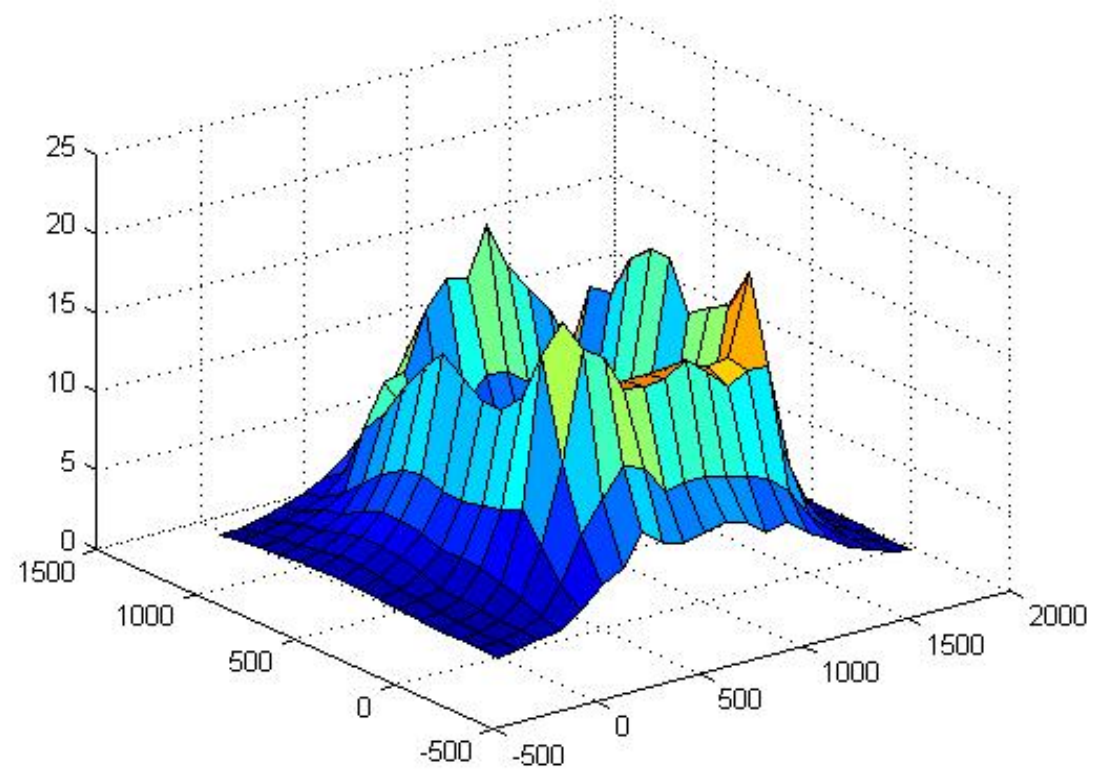

With chassis

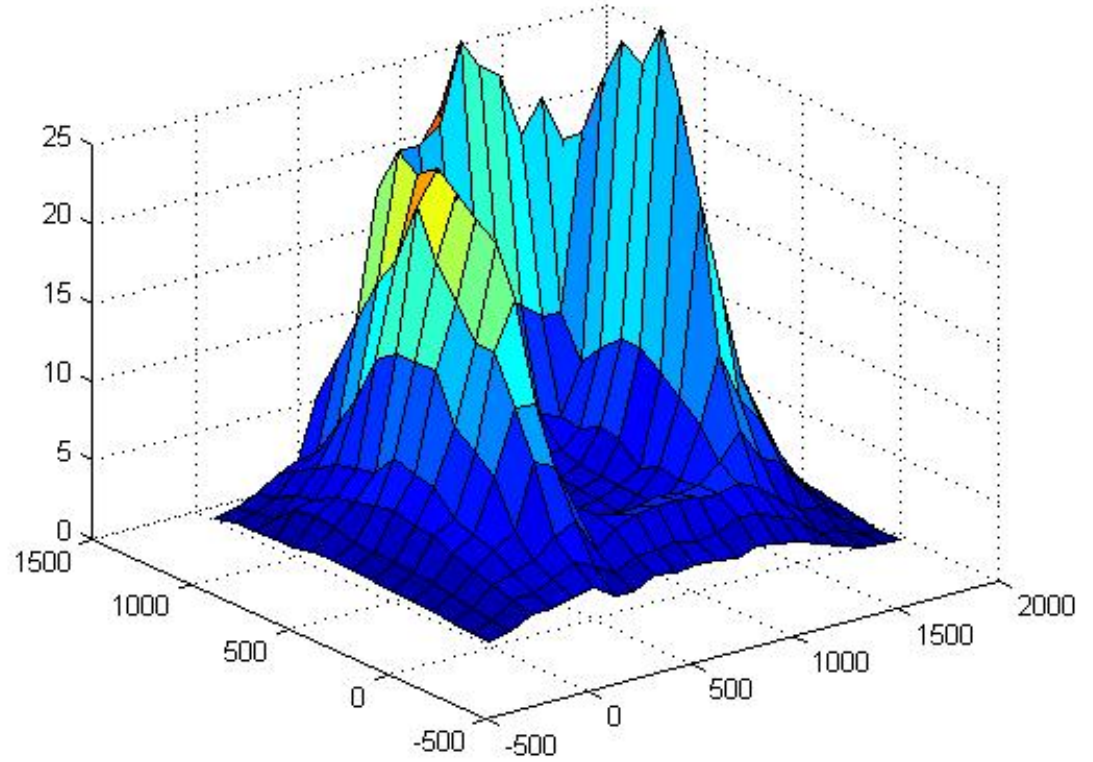

Without chassis 


\section{Effect of Misalignment}

$>$ Coil spacing is $200 \mathrm{~mm}$.

$>15 \mathrm{~kW}$ output power;

$>$ MFD is measured $300 \mathrm{~mm}$ above ground.

How is the magnetic field distribution for--

aligned and misaligned coils, with/without chassis? 


\section{Effect of Misalignment}

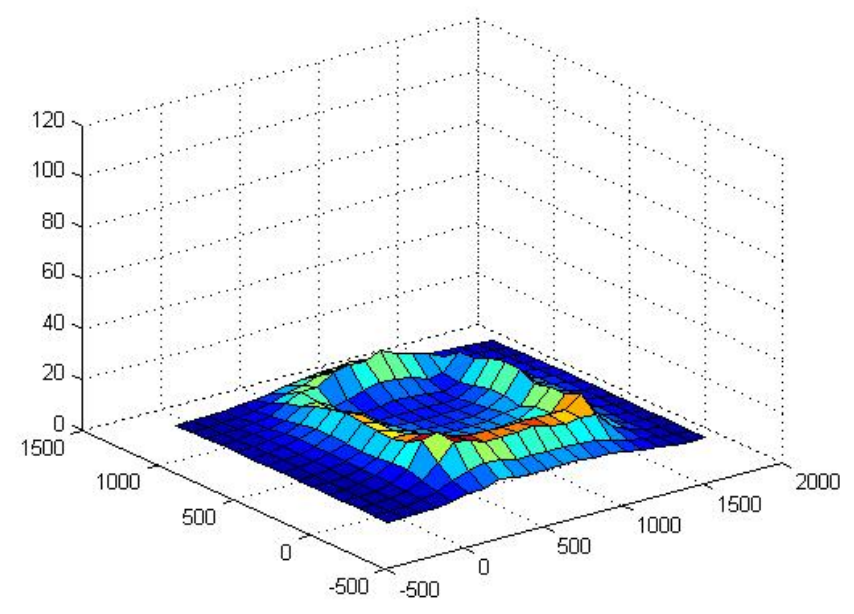

Aligned, with chassis

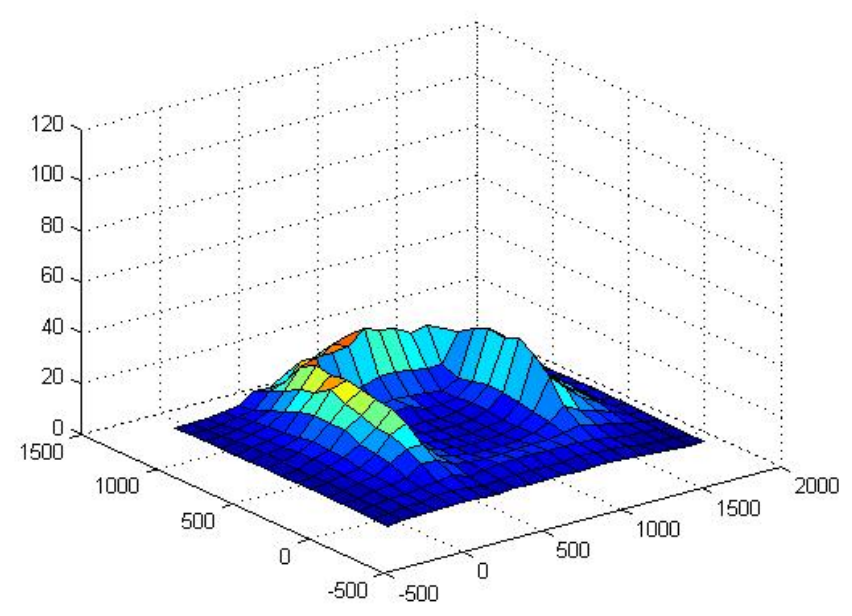

Aligned, no chassis

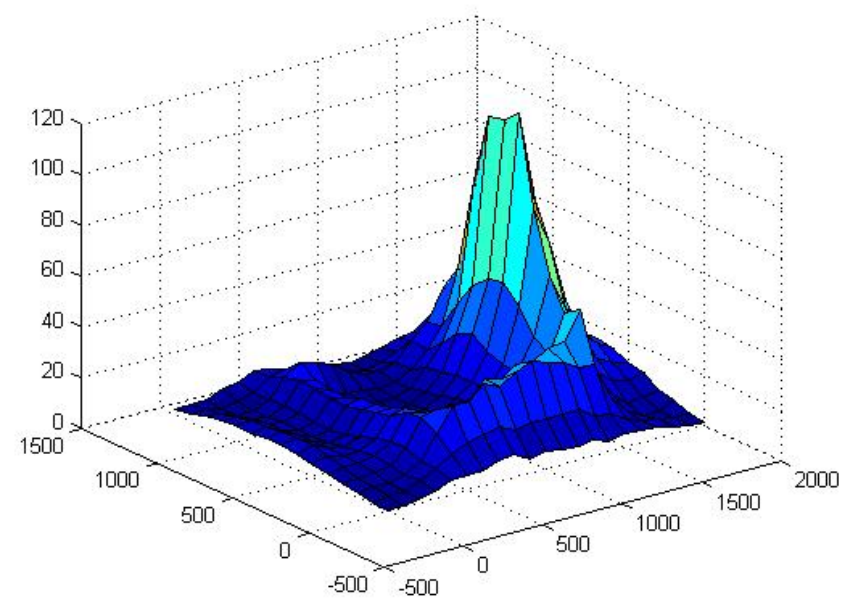

$200 \mathrm{~mm}$ misaligned, with chassis

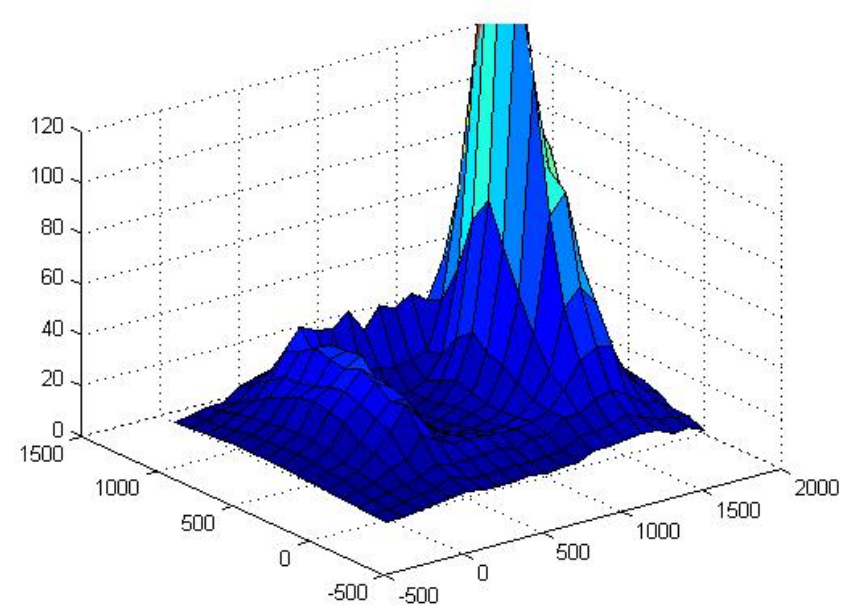

$200 \mathrm{~mm}$ misaligned, no chassis 


\section{Conclusion}

1. We have studied the impact of four parameters on the magnetic field distribution in wireless power transfer system for EVs.

2. We have verified that the magnetic field distribution is proportional to the square root of output power.

3. Small gap leads to smaller fringing fields.

4. Inclusion of chassis in the system effectively shields the magnetic field.

5. Misalignment between coils increases the magnetic field. 